\title{
Estudio de las Interacciones Ácido Húmico-Metales Pesados y Determinación de sus Constantes de Estabilidad por Electroforesis Capilar
}

\author{
Silvia Nieto-Velázquez, Lourdes Pacheco-Hernández, Carlos A. Galán-Vidal y \\ María E. Páez-Hernández* \\ Lab. de Química Analítica, Área Académica de Química, Universidad Autónoma del Estado de \\ Hidalgo, Carr. Pachuca-Tulancingo, Km. 4.5. Mineral de la Reforma, C.P 42184. Hidalgo-México \\ (e-mail: paezh@uaeh.edu.mx)
}

*Autor a quien debe ser dirigida la correspondencia

Recibido Jun. 14, 2010; Aceptado Jul. 28, 2010; Versión Final recibida Sep. 29, 2010

\begin{abstract}
Resumen
La técnica de electroforesis capilar asociada con el programa computacional SQUAD ha sido empleada para el estudio de la interacción entre metales pesados $\left(\mathrm{Cu}^{2+}, \mathrm{Pb}^{2+}, \mathrm{Hg}^{2+}, \mathrm{Co}^{2+}, \mathrm{Cd}^{2+}\right)$ y un ácido húmico. Dicha interacción, provoca el desplazamiento en el tiempo de migración de los metales en función de la concentración del ácido. De esta información es posible obtener las movilidades electroforéticas efectivas y alimentarlas al programa SQUAD para calcular las constantes de equilibrio considerando una estequiometría 1:1. La afinidad del ácido húmico hacia los metales decrece en el siguiente orden: $\mathrm{Cu}^{2+}>\mathrm{Pb}^{2+}>\mathrm{Hg}^{2+}>\mathrm{Co}^{2+}>\mathrm{Cd}^{2+}$. Las respectivas constantes de equilibrio son: (log $\left.\beta_{1}\right)$ : $3.48 \pm 0.33,3.62 \pm 0.24,3.18 \pm 0.19,2.96 \pm 0.20$ y $2.58 \pm 0.33$. Esta tendencia coincide con la teoría ABDB de Pearson y con otros datos de la literatura.
\end{abstract}

Palabras claves: ácidos húmicos, electroforesis capilar, SQUAD, constantes de estabilidad, afinidad

\section{Study of Humic Acid-Heavy Metal Interactions and the Evaluation of its Stability Constants by Capillary Electrophoresis}

\begin{abstract}
The capillary electrophoresis technique associated with the SQUAD computer program has been used to study the interaction between humic acid and heavy metals $\left(\mathrm{Cu}^{2+}, \mathrm{Pb}^{2+}, \mathrm{Hg}^{2+}, \mathrm{Co}^{2+}, \mathrm{Cd}^{2+}\right)$. Such interaction causes a shift in the migration time of metals depending on the concentration of humic acid. From this information the effective electrophoretic mobility was determined and then introduced to the SQUAD program to calculate the equilibrium constants considering a 1:1 stoichiometry. The affinity of humic acid to the metals decreases in the following order: $\mathrm{Cu}^{2+}>\mathrm{Pb}^{2+}>\mathrm{Hg}^{2+}>\mathrm{Co}^{2+}>\mathrm{Cd}^{2+}$. The respective equilibrium constants $\left(\log \beta_{1}\right)$ are: $3.48 \pm 0.33,3.62 \pm 0.24,3.18 \pm 0.19,2.96 \pm 0.20$ and 2.58 \pm 0.33 . This tendency is consistent with the Pearson HSAB theory and with other data published in the literature.
\end{abstract}

Keywords: humic acid, capillary electrophoresis, SQUAD, stability constant, affinity 


\section{INTRODUCCIÓN}

El suelo es un sistema abierto, dinámico, constituido por tres fases. La fase sólida está formada por componentes inorgánicos y orgánicos, que dejan un espacio de huecos (poros, cámaras, galerías, grietas y otros) en el que se hallan las fases líquida y gaseosa. Por su constitución, los suelos son sistemas complejos de enorme trascendencia ya que soportan la vida suministrando nutrientes y energía para el crecimiento de las plantas y el desarrollo de los animales (Porta Casanellas, 2008).

Los componentes orgánicos del suelo pueden dividirse en dos clases de material: el no-húmico (por ejemplo proteínas, polisacáridos, ácidos nucléicos y pequeñas moléculas de azúcar y aminoácidos) y las sustancias húmicas (SHs) (Stevenson, 1994). Estas últimas son consideradas como polielectrolitos biogénicos que poseen una estructura macromolecular con un gran número de grupos $\mathrm{OH}$ y $\mathrm{COOH}$, y con amplio rango de pesos moleculares (Schnitzer y Khan, 1972). Las sustancias húmicas son ligandos orgánicos que juegan un rol crucial en la especiación, transporte y deposición de una gran variedad de compuestos que van desde iones metálicos hasta compuestos lipofílicos (Livens, 1991).

De acuerdo a su solubilidad en medio acuoso, las $\mathrm{SH}$ pueden separarse en Ácidos Fúlvicos (AFs) (soluble a todos los valores de $\mathrm{pH}$ ), Huminas ( $\mathrm{Hu}$ ) (insolubles a todos los valores de $\mathrm{pH}$ ) y en Ácidos Húmicos (HAs) (solubles en medio alcalino e insolubles a pH menor a 2) (Janoš, 2003). Cada una de estas sustancias juega un papel particular en el medio ambiente; así, mientras que los AF pueden formar complejos metálicos más solubles, biodisponibles y móviles debido a su menor tamaño molecular y gran contenido de grupos funcionales ácidos, los HA tienden a inmovilizar y a acumular al metal en la fase sólida del suelo (Stevenson, 1994) por lo que se considera que controlan la absorción radicular de metales por las plantas (Evans, 1989). De esta forma, los ácidos húmicos pueden ser utilizados en tratamientos de descontaminación en suelos y lagos (Perminova y Hatfield, 2005) siendo su capacidad complejante ampliamente estudiada para metales pesados (Lubal et al., 1998), elementos radioactivos (Lubal et al., 2000) e incluso halógenos (Myneni, 2002), ácidos orgánicos (Cozzolino et al., 2001), pesticidas y herbicidas (Gevao et al., 2000).

El amplio interés de la comunidad científica por la interacción entre los HAs y los iones metálicos ha favorecido su estudio mediante diversos métodos analíticos como: voltametría de redisolución anódica (Chakraborty, 2010), potenciometría con electrodos selectivos de iones (Sikora y Stevenson, 1988), ultrafiltración (Nifant'eva et al., 2001), intercambio iónico (Wenming et al., 2002a; Wenming et al., 2002b; Baker y Khalili, 2005), diálisis (Glaus et al., 2000) y espectrofotometría (Bai et al, 2008), entre otras. En los últimos años, la electroforesis capilar ha destacado como una técnica de separación poderosa, rápida y eficiente que ha permitido la caracterización de HAs por huella digital (fingerprint) y contribuir a su elucidación estructural mediante el fraccionamiento de dichas moléculas (Vanifatova et al, 2008), además de proporcionar información útil para estudios de especiación mediante la determinación de constantes de equilibrio (Stern et al., 2007; Lubal et al., 1998).

En el presente trabajo se reporta una metodología eficiente para la determinación de constantes de complejación HA-metal mediante electroforesis capilar y el refinamiento de la información experimental con el programa computacional SQUAD (Leggett y McBryde, 1975). Se trabajó con un HA comercial de elevada pureza (obtenido del carbón) y diferentes iones metálicos contaminantes representativos $\left(\mathrm{Cu}^{2+}, \mathrm{Hg}^{2+}, \mathrm{Pb}^{2+}, \mathrm{Cd}^{2+}\right.$ y $\left.\mathrm{Co}^{2+}\right)$.

\section{METODOLOGÍA}

\section{Equipo}

Todos los experimentos fueron llevados a cabo en un equipo de electroforesis capilar Beckman Coulter (Modelo P/ACE MDQ) (Palo Alto,CA, USA) equipado con un detector UV/Vis. Se utilizó un 
capilar de sílice fundida de $39 \mathrm{~cm}$ de longitud total $(28.5 \mathrm{~cm}$ al detector) de $50 \mu \mathrm{m}$ de diámetro interno. El voltaje aplicado fue de $20 \mathrm{kV}$ (polaridad normal) y la temperatura se mantuvo a $25^{\circ} \mathrm{C}$. Las muestras fueron inyectadas hidrodinámicamente aplicando 3 psi de presión durante 5 segundos y la absorbancia fue seguida a $214 \mathrm{~nm}$.

Inicialmente el capilar fue activado a $40^{\circ} \mathrm{C}$ por 10 min con $\mathrm{NaOH} 1.0 \mathrm{M}$, seguido de $\mathrm{NaOH} 0.1 \mathrm{M}$ a $40^{\circ} \mathrm{C}$ por $10 \mathrm{~min}$; posteriormente se enjuaga con agua desionizada a $30^{\circ} \mathrm{C}$ por $10 \mathrm{~min}$ y finalmente se hace pasar el buffer de trabajo a $25^{\circ} \mathrm{C}$ por $10 \mathrm{~min}$ (Pacheco, 2002). Entre cada inyección el capilar se lava durante 1 min con $\mathrm{NaOH} 0.1 \mathrm{M}, 3$ min con agua deionizada y 3 min con el buffer de trabajo, todo a $25^{\circ} \mathrm{C}$.

\section{Disoluciones}

El ácido húmico utilizado se obtuvo comercialmente de Chemapex Praha S.R.O. (Praga, República Checa); posee escasa materia inorgánica lo que se refleja en un bajo contenido de cenizas (1.12\%). Por medio del análisis elemental se determinaron los porcentajes totales de los componentes elementales (carbono, hidrógeno y nitrógeno) a partir de las muestras sólidas de $\mathrm{AHs}$, en un Analizador Elemental Perkin Elmer Serie II CHNS/0 2400. La relación entre átomos H/C muestra un carácter predominantemente aromático debido a su bajo valor (0.9) (Stevenson, 1994). Esto se corroboró a través del cálculo del porcentaje de aromaticidad con ayuda de un estudio espectrofotométrico (Stevenson, 1994) realizado en un Espectrofotómetro UV/Vis Lambda 40, Perkin Elmer, resultando en un $73.84 \%$.

La disolución madre del $\mathrm{AH} 0.01 \mathrm{~mol} \mathrm{~L}^{-1}$ se preparó disolviendo la cantidad adecuada de ácido húmico en $\mathrm{NaOH} 0.04 \mathrm{M}$ (Pacheco, 2002). Considerando el peso molecular correspondiente a la fórmula empírica del AH propuesta por Davies y colaboradores (Davies et al., 1997) la disolución $10,000 \mathrm{mg} \mathrm{L}^{-1}$ del ácido húmico equivale a una concentración $10 \mathrm{mmol} \mathrm{L}^{-1}$. A partir de ésta se realizó una dilución para obtener otra $1 \mathrm{mmol} \mathrm{L}^{-1}$ del $\mathrm{AH}$.

Las disoluciones madre $0.01 \mathrm{~mol} \mathrm{~L}^{-1}$ de cada metal bivalente $(\mathrm{Cu}, \mathrm{Hg}, \mathrm{Pb}, \mathrm{Cd}$ y $\mathrm{Co})$ fueron preparadas disolviendo las sales de nitrato correspondientes (Aldrich, USA) en agua desionizada $(18 \mathrm{M} \Omega \mathrm{cm})$. A partir de cada disolución madre se prepararon diluciones $1 \mathrm{mmol} \mathrm{L}^{-1}$ para cada metal.

Para el análisis electroforético de las mezclas Me-HA se utilizó como buffer de trabajo una disolución de acetatos $\left(\mathrm{CH}_{3} \mathrm{COOH} / \mathrm{CH}_{3} \mathrm{COONa}\right)$ de concentración total $50 \mathrm{mmol} \mathrm{L}{ }^{-1}$, ajustado a $\mathrm{pH}=3.5$.

Previo a su uso en electroforesis capilar, todas las disoluciones fueron filtradas a través de filtros de tamaño de poro de $0.45 \mu \mathrm{m}$ (Millipore, MA, USA) e introducidas en un baño sonicador por 20 min.

\section{Procedimiento}

Para el cálculo de las constantes de equilibrio se prepararon diversas disoluciones que contenían la misma cantidad del metal $\left(\mathrm{M}^{2+}\right) 1 \mathrm{mmol} \mathrm{L}^{-1} \mathrm{y}$ a las cuales se les adicionó $\mathrm{AH} 10 \mathrm{mmol} \mathrm{L^{-1 }}$ con el objeto de contar con mezclas [Me]-[AH] de relaciones estequiométricas mayores y menores a la equimolar (1:1). Una vez preparadas, estas disoluciones se analizaron por EC siguiendo el procedimiento descrito anteriormente.

\section{Cálculos}

Asumiendo la constante global de complejación general:

$$
\beta_{\mathrm{n}}=\frac{\left[\mathrm{ML}_{\mathrm{n}}\right]}{[\mathrm{M}][\mathrm{L}]^{\mathrm{n}}}
$$


la movilidad efectiva $\mu_{\text {eff }}$ de un catión metálico $M$ en presencia de un ligante complejante $L$, puede expresarse, omitiendo las cargas por simplicidad, como:

$$
\mu_{\text {eff }}=\frac{\sum_{\mathrm{i}=0}^{\mathrm{n}} \mu_{\mathrm{ML}_{\mathrm{i}}} \beta_{\mathrm{i}}[\mathrm{L}]^{\mathrm{i}}}{\sum_{\mathrm{i}=0}^{\mathrm{n}} \beta_{\mathrm{i}}[\mathrm{L}]^{\mathrm{i}}}=\frac{\mu_{\mathrm{M}} \beta_{0}+\mu_{\mathrm{ML}} \beta_{1}[\mathrm{~L}]+\mu_{\mathrm{ML}_{2}} \beta_{2}[\mathrm{~L}]^{2}+\ldots+\mu_{\mathrm{ML}_{n}} \beta_{\mathrm{n}}[\mathrm{L}]^{\mathrm{n}}}{\beta_{0}+\beta_{1}[\mathrm{~L}]+\beta_{2}[\mathrm{~L}]^{2}+\ldots+\beta_{\mathrm{n}}[\mathrm{L}]^{\mathrm{n}}}
$$

donde $\mu_{\mathrm{MLi}}$ son las movilidades de las especies individuales y $\beta_{\mathrm{i}}$ representa el conjunto de constantes de estabilidad de los complejos formados entre el $\mathrm{AH}$ y el ion metálico ( $\beta_{0}$ es igual a 1 ).

En este trabajo, las constantes de equilibrio fueron estimadas usando el programa computacional SQUAD (Leggett, 1975). Los cálculos se basan en la minimización de la suma de los cuadrados de las diferencias entre las movilidades efectivas experimentales $\mu_{\text {eff, exp }}$ y las movilidades calculadas $\mu_{\text {eff, }}$ calc. Así, parámetros como las constantes de equilibrio y las movilidades de los iones individuales son calculadas a partir de la minimización de $U$ de acuerdo a la ecuación:

$\mathrm{U}=\sum_{\mathrm{i}}\left(\mu_{\text {eff }, \exp }-\mu_{\text {eff }, \mathrm{calc}}\right)^{2}=$ mínimo

donde la sumatoria se considera sobre todos los puntos experimentales $i$, mientras que la movilidad efectiva experimental del metal M $\left(\mu_{\text {eff, exp }}\right)$ puede determinarse por medio de la siguiente ecuación:

$\mu_{\text {eff }, \exp }=\frac{\mathrm{L}_{\text {tot }} \cdot \mathrm{L}_{\text {det }}\left(1 / \mathrm{t}_{\mathrm{m}}-1 / \mathrm{t}_{\mathrm{FEO}}\right)}{\mathrm{V}}$

donde $L_{\text {tot }} y L_{\text {det }}$ son la longitud total de capilar y la longitud al detector, respectivamente; $V$ es el voltaje impuesto, $t_{m}$ el tiempo de migración y $t_{F E O}$ el tiempo del salida del flujo electrosmótico.

\section{RESULTADOS Y DISCUSION}

\section{Efecto del buffer en la reacción de complejación M-AH}

La electroforesis capilar es una técnica empleada para la separación de analitos cargados eléctricamente en un medio conductor (generalmente una disolución buffer) bajo la influencia de un campo eléctrico. Así, puede inferirse que la elección del medio conductor es un factor fundamental tanto para movilidad de los analitos como para su separación en una mezcla compleja debido al pH impuesto.

A pesar de los beneficios que el buffer puede aportar a una separación electroforética, es importante considerar que sus constituyentes pueden interaccionar con el analito al pH de trabajo, formando complejos de diferentes cargas y estequiometrías. Así, si el objeto de la investigación es el estudio de la interacción de un analito con un ligante, la formación de un complejo estable analito-buffer puede ser contraproducente. De acuerdo a lo anterior, en este trabajo se requirió de un buffer cuyos constituyentes no formaran complejos con el ion metálico que evitaran su interacción con el ácido húmico. Diversos buffers fueron considerados y su interacción con el ion metálico estudiada construyendo Diagramas de Distribución (DD) para cada metal y para cada posible constituyente (oxalato, acetato, citrato y fosfato, entre otros) (Puigdomenech, 2000). Con DD's como el mostrado en la Figura 1, fue posible elegir el buffer, la concentración y el $\mathrm{pH}$ adecuados para el análisis.

En la Figura 1, es posible observar que en el intervalo de $\mathrm{pH}$ de 3 a 4, el metal puede interaccionar con los grupos negativos de la molécula del $\mathrm{AH}$, ya sea como $\mathrm{M}^{2+}$ o como $\mathrm{M}\left(\mathrm{CH}_{3} \mathrm{COO}\right)^{+}$. De esta 
forma, y haciendo un análisis similar para el resto de los metales en estudio se eligió el pH de 3.5 para todos los análisis por EC.

Estudio de la complejación ion metálico-AH por EC

La capacidad de complejación del AH con los iones metálicos en estudio se evaluó por EC. En estos experimentos las disoluciones preparadas tenían la misma concentración del metal pero diferentes concentraciones de $\mathrm{AH}$, originando así, mezclas con relaciones M/HA variadas. La Figura 2 muestra los electroferogramas representativos de estos estudios.

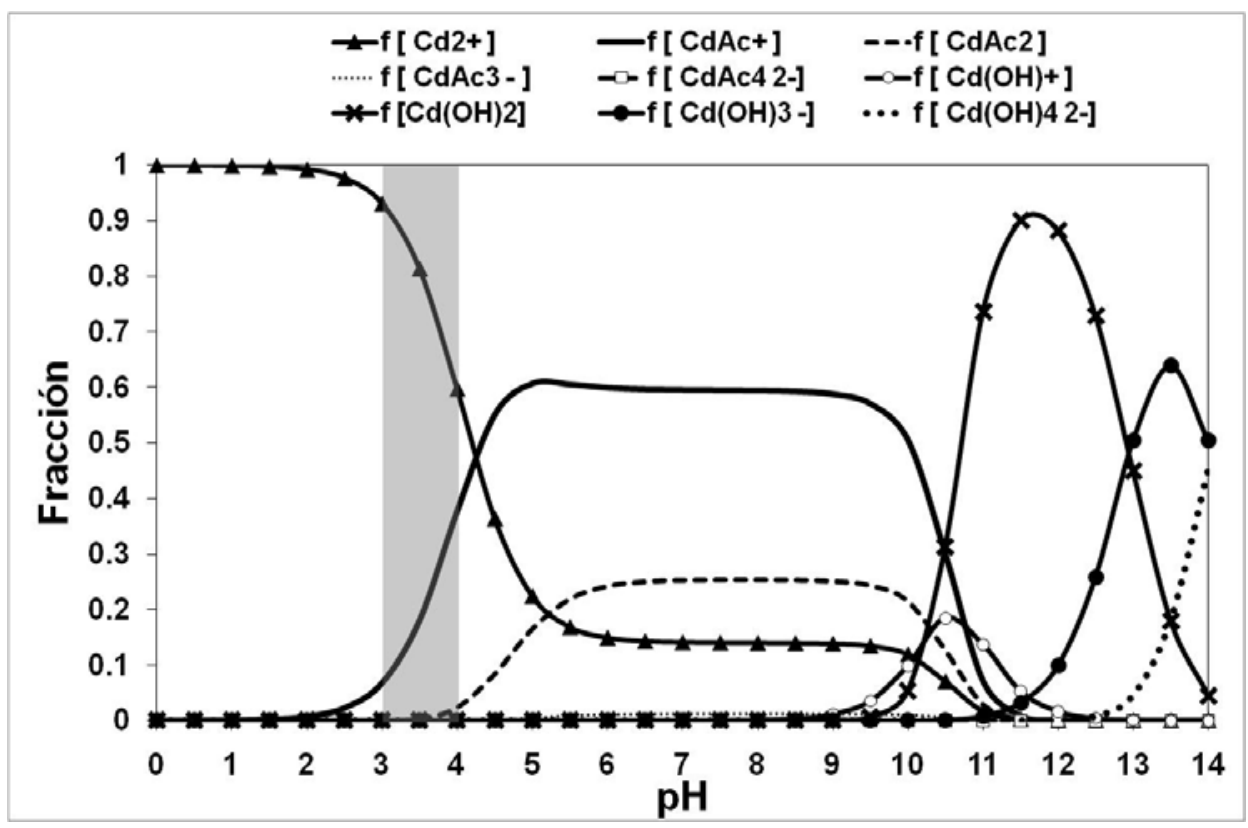

Fig. 1. Diagrama de Distribución de Especies para el sistema Cd(II) / Acetato (Ac) / $\mathrm{H}_{2} \mathrm{O}$, construido con el programa MEDUSA (Puigdomenech, 2000). Condiciones $[\mathrm{M}(\mathrm{II})]=1 \mathrm{mmol}$ $\mathrm{L}^{-1},[\mathrm{Ac}]_{\mathrm{T}}=50 \mathrm{mmol} \mathrm{L}^{-1}$.

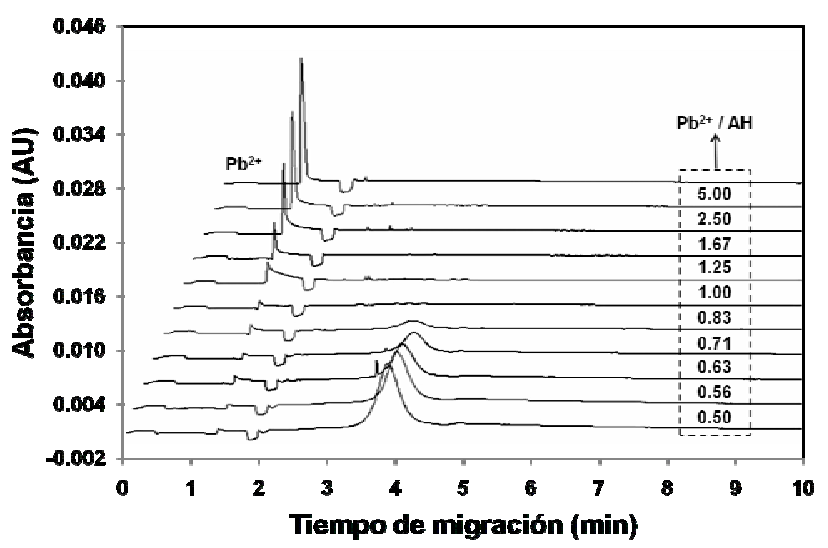

(a)

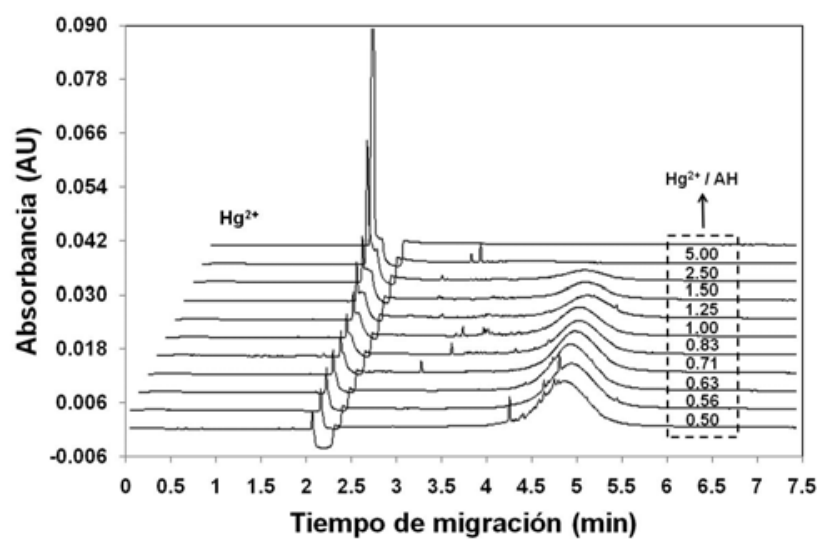

(b)

Fig. 2. Electroferograma de mezclas (a) $\mathrm{Pb}(\mathrm{II})-\mathrm{AH}-\mathrm{Chemapex} \mathrm{y} \mathrm{(b)} \mathrm{Hg}(\mathrm{II})-\mathrm{AH}-\mathrm{Chemapex} \mathrm{en} \mathrm{diferentes}$ proporciones, partiendo de una disolución $1 \mathrm{mmol} \mathrm{L}^{-1}$ del metal. Buffer de acetatos a $\mathrm{pH}=3.5$, inyección hidrodinámica $5 \mathrm{~s}$, presión de inyección 3 psi a $25^{\circ} \mathrm{C}$, voltaje de separación $20 \mathrm{kV}$, capilar de sílice fundida, polaridad normal. 
En la Figura 2a se observan los cambios en la intensidad y el $t_{m}$ de la señal de $\mathrm{Pb}(\mathrm{II})$ cuando se adicionaron diferentes concentraciones de $\mathrm{AH}$. El aumento en el tiempo de migración de la señal del metal se atribuye a la reacción de neutralización de su carga llevada a cabo con las moléculas de $\mathrm{AH}$ (negativas). La formación de especies neutras se sustenta en el desplazamiento de la señal del $\mathrm{Pb}$ (II) hacia el pico del marcador neutro (señal alrededor de 2 min con intensidad negativa). Así, conforme se incrementa la concentración de $\mathrm{AH}$ en las disoluciones del metal, la intensidad del pico del metal disminuye apreciablemente, mientras que aparece una señal a $t_{m}$ superiores a la del marcador neutro, la cual es atribuible al $\mathrm{AH}$, indicio de que se encuentra en exceso.

En el caso del $\mathrm{Hg}(\mathrm{II})$ (Fig. 2b), la interacción con el $\mathrm{AH}$ parece ser de menor intensidad que en el caso anterior, ya que su señal nunca desaparece del todo, ni aún a altas concentraciones del AH. No obstante, la formación de un complejo $\mathrm{Hg}$ (II)-AH es comprobable por el desplazamiento de la señal del $\mathrm{Hg}(\mathrm{II})$ nuevamente a tiempos cercanos al del marcador neutro. Sin embargo, y con el objeto únicamente de evidenciar la interacción $\mathrm{Hg}-\mathrm{AH}$ se realizó un electroferograma adicional en donde a una disolución de $\mathrm{AH}$ se le adicionaron progresivamente diferentes cantidades de una disolución de $\mathrm{Hg}^{2+}$. Los resultados de este experimento se muestran en la Figura 3.

En la Fig. 3 puede apreciarse que el primer electroferograma (sólo ácido húmico) revela señales posteriores al tiempo del flujo electrosmótico. Este comportamiento es típico para moléculas aniónicas como el $\mathrm{AH}$ y ha sido reportado anteriormente (Vanifatova et al, 2008). Este electroferograma se ve altamente afectado conforme se adiciona mercurio(II) a la disolución del húmico y continúa hasta la desaparición completa de las señales del $\mathrm{AH}$ como resultado de la interacción entre estas dos especies.

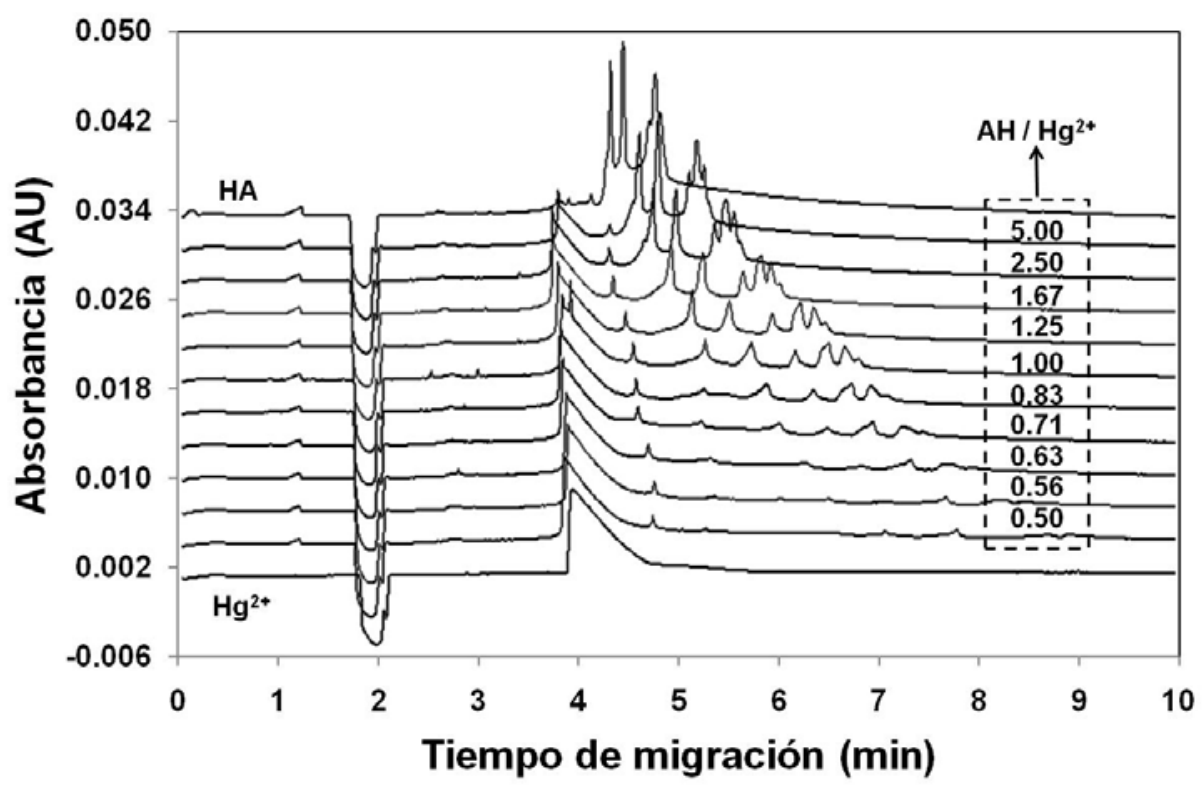

Fig. 3. Electroferograma de mezclas $\mathrm{Hg}(\mathrm{II})-\mathrm{AH}-\mathrm{Chemapex}$ en diferentes proporciones, partiendo de una disolución $1 \mathrm{mmol} \mathrm{L}^{-1}$ del $\mathrm{AH}$. Buffer: ácido bórico $90 \mathrm{mmol} \mathrm{L}^{-1}+$ Tris (hidroximetil aminometano) $115 \mathrm{mmol} \mathrm{L}^{-1}+$ EDTA $0.75 \mathrm{mmol} \mathrm{L}^{-1}, \mathrm{pH}=8.5$, inyección hidrodinámica $5 \mathrm{~s}$, presión de inyección 3 psi a $25^{\circ} \mathrm{C}$, voltaje de separación $20 \mathrm{kV}$, capilar de sílice fundida, polaridad normal.

\section{Determinación de las constantes de estabilidad de los complejos metal-AH}

En los últimos años, un gran número de técnicas han sido desarrolladas para evaluar las constantes de estabilidad, la mayoría de ellas basadas en técnicas de separación bajo condiciones de equilibrio. 
Dentro de estas técnicas de separación, la electroforesis capilar ha demostrado ser una herramienta analítica poderosa por su gran eficiencia, alto poder de resolución y sus cortos tiempos de análisis (Garrison et al., 1995). Empleando esta técnica y a partir de los electroferogramas obtenidos para cada mezcla M-AH (Fig. 2) se calcularon las movilidades efectivas $\mu_{\text {eff }}$ para cada metal por medio de la ecuación 4. Dichos valores se alimentaron al programa SQUAD obteniéndose los resultados reportados en la Tabla 1.

Tabla 1. Constantes de equilibrio AH-Metal.

\begin{tabular}{|c|c|}
\hline Ion metálico & $\begin{array}{c}\text { Constante de equilibrio } \\
\left(\log \beta_{1}\right)\end{array}$ \\
\hline $\mathrm{Cd}(\mathrm{II})$ & $2.58 \pm 0.327$ \\
\hline $\mathrm{Co}(\mathrm{II})$ & $2.96 \pm 0.199$ \\
\hline $\mathrm{Cu}$ (II) & $3.62 \pm 0.243$ \\
\hline $\mathrm{Hg}$ (II) & $3.18 \pm 0.186$ \\
\hline $\mathrm{Pb}$ (II) & $3.48 \pm 0.328$ \\
\hline
\end{tabular}

Cabe resaltar que la mejor convergencia fue considerando una relación estequiométrica 1:1 (modelo "single site"), en congruencia con reportes previos (Lu y Raffe, 2001; Bai, 2008). Es importante aclarar que los valores que se muestran en la Tabla 1 son constantes condicionales, es decir, considerando la influencia del buffer y del pH impuesto durante los experimentos.

Los resultados obtenidos sobre la afinidad del metal con el $\mathrm{AH}$ muestran la siguiente tendencia $\mathrm{Cu}^{2+}>\mathrm{Pb}^{2+}>\mathrm{Hg}^{2+}>\mathrm{Co}^{2+}>\mathrm{Cd}^{2+}$. Esta tendencia coincide con reportes anteriores (Pandey et al., 2000; Lubal et al., 1998) y con la teoría ABDB (Pearson, 1963), que establece la preferencia de las bases duras como los grupos fenolato o carbonilo a enlazarse con metales de características de un ácido duro o de dureza media como el $\mathrm{Cu}^{2+}, \mathrm{Pb}^{2+} \mathrm{O} \mathrm{Co}^{2+}$, sobre aquellos que se consideran ácidos blandos $\left(\mathrm{Cd}^{2+}\right)$. Sin embargo, es importante resaltar que si bien el $\mathrm{Hg}^{2+}$ es considerado un ácido blando, es muy conocida la fuerte interacción entre este metal y los ácidos húmicos (Zhang et al., 2009) lo que demuestra el importante papel que juegan los AHs en el control de la contaminación por mercurio en el medio ambiente.

\section{CONCLUSIONES}

El estudio realizado muestra claramente la existencia de interacciones entre los ácidos húmicos y los metales pesados. Estas interacciones pueden ser de utilidad para la inmovilización de metales pesados en aguas y suelos como estrategia de remediación de la contaminación.

La EC en asociación con el programa computacional SQUAD es una metodología sencilla, rápida y económica para la determinación de constantes de complejación.

\section{AGRADECIMIENTOS}

S.N.V. agradece al Consejo Nacional de ciencia y Tecnología (CONACYT) la beca otorgada para la realización de sus estudios de posgrado. C.A.G.V. y M.E.P.H. agradecen al SNI-CONACyT el reconocimiento y apoyo económico recibido.

\section{REFERENCIAS}

Bai, Y.C. y otros siete autores, Ultraviolet absorbance titration for determining stability constants of humic substances with Cu(II) and Hg(II, Analytica Chimica Acta: 616, 115-121 (2008). 
Baker, H. y F. Khalili, A study of complexation thermodynamic of humic acid with cadmium (II) and zinc (II) by Schubert's ion-exchange method, Analytica Chimica Acta: 542, 240-248 (2005).

Cozzolino, A., P. Conte y A. Piccolo, Conformational changes of humic substances induced by some hydroxy-, keto-, and sulfonic acid, Soil Biology \& Biochemistry: 33, 563-571 (2001).

Chakraborty, P., Study of cadmium-humic interactions and determination of stability constants of cadmium-humate complexes from their diffusion coefficients obtained by scanned stripping voltammetry and dynamic light scattering techniques, Analytica Chimica Acta: 659, 137-143 (2010).

Davies, G., et al. Tight metal binding by humic acids and its role in biomineralizatio, Journal of Chemical Society, Dalton Transactions: 21, 4047-4060 (1997).

Evans, L.J., Chemistry of metal retention by soils, Environmental Science \& Technology: 23, 10481056 (1989).

Garrison, A. W., P. Schmitt y A. Kettrup, Capillary electrophoresis for the characterization of humic substance, Water Research: 29(9), 2149-2159 (1995).

Gevao, B., K.T. Semple y K.C. Jones, Bound pesticide residues in soils: a review, Environmental Pollution: 108, 3-14 (2000).

Glaus, M.A., W. Hummel y L.R. Van Loon, Trace metal-humate interactions. I. Experimental determination of conditional stability constants, Applied Geochemistry: 15, 953-973 (2000).

Janoš, P., Separation methods in the chemistry of humic substances, J. Chromatography A: 983 (1-2), 1-18, (2003).

Leggett, D.J. y W.A.E. McBryde, General computer program for the computation of stability constants from absorbance data, Analytical Chemistry: 47(7), 1065-1070 (1975).

Livens, F.R., Chemical reactions of metals with humic material, Environmental Pollution: 70(3), 183208 (1991).

Lu, X.Q. y R. Jaffe, Interaction between $\mathrm{Hg}(\mathrm{II})$ and natural dissolved organic matter: A fluorescence spectroscopy based study, Water Research: 35(7), 1793-1803 (2001).

Lubal, P. y otros cinco autores, Potentiometric and spectroscopic study of uranyl complexation with humic acids, Talanta, 51(5), 977-991 (2000).

Lubal, P., D. Siroky, D. Fetsch y J. Havel, The acidobasic and complexation properties of humic acids - Study of complexation of Czech humic acids with metal ions, Talanta: 47(2), 401-412 (1998).

Myneni, S.C.B., Formation of stable chlorinated hydrocarbons in weathering plant material, Science: 295(5557), 1039-1041 (2002).

Nifant'eva, T.I. y otros cuatro autores, Ultrafiltration and determination of $\mathrm{Zn}$ - and Cu-humic substances complexes stability constants, Talanta, 53, 1127-1131 (2001).

Pacheco, M.L., Capillary Electrophoresis and MALDI-TOF Mass Spectrometry of Humic Acids, Tesis de Doctorado, Departamento de Química Analítica, Facultad de Ciencias, Universidad de Masaryk, República Checa (2002). 
Pandey, A.K., S.D. Pandey y V. Misra, Stability constants of metal-humic acid complexes and its role in environmental detoxification. Ecotoxicology and Environmental Safety: 47, 195-200 (2000).

Pearson, R.G., Hard and soft acids and bases, Journal of American Chemical Society: 85 (22), 35333539 (1963).

Perminova, I.V. y K. Hatfield, Remediation chemistry of humic substances: theory and implications for technology, In Use of humic substances to remediate polluted environments: from theory to practice by I.V. Perminova, K. Hatfield y N. Hertkorn, pp 3-35. Springer, Holanda (2005).

Porta, J., M. López-Acevedo y C. Roquero, Edafología: para la agricultura y el medio ambiente, 3a. edición, Mundi-Prensa, España (2008).

Puigdomenech, I., Windows software for the graphical presentation of chemical speciation, Actas del 219th American Chemical Society National Meeting, 1, 248, San Francisco, Estados Unidos, 26 a 30 de Marzo (2000).

Schnitzer, M. y S.U. Khan, Humic substances in the environment, 65-110, Marcel Dekker, Nueva York, EUA (1972).

Sikora, F.J. y F.J. Stevenson, Silver complexation by humic substances: conditional stability constants and nature of reactive sites, Geoderma, 42, 353-363 (1988).

Stern, J.C., J.E. Sonke y V.J.M. Salters, A capillary electrophoresis-ICP-MS study of rare earth element complexation by humic acids, Chemical Geology: 246, 170-180 (2007).

Stevenson, F.J., Humus chemistry: genesis, composition, reactions, $2^{\mathrm{a}}$ edición, 6-19, John wiley \& Sons, Inc., Nueva York, EUA (1994).

Vanifatova, N.G., A.G. Zavarzina y B.Y. Spivakov, Potential of capillary zone electrophoresis for estimation of humate acid-base properties, Journal of Chromatography A: 1183, 186-191 (2008).

Wenming D., Z. Hongxia, H. Meide y T. Zuyi, Use of the ion exchange method for the determination of stability constants of trivalent metal complexes with humic and fulvic acids-Part I: $\mathrm{Eu}^{3+}$ and $\mathrm{Am}^{3+}$ complexes in weakly acidic conditions, Applied Radiation and Isotopes: 56, 959-965 (2002a).

Wenming D., L. Weijuan y T. Zuyi, Use of the ion exchange method for the determination of stability constants of trivalent metal complexes with humic and fulvic acids $I I . \mathrm{Tb}^{3+}, \mathrm{Yb}^{3+}$ and $\mathrm{Gd}^{3+}$ complexes in weakly alkaline condition, Applied Radiation and Isotopes: 56, 967-974 (2002b).

Zhang, J. y otros cuatro autores, Adsorption and desorption of divalent mercury $\left(\mathrm{Hg}^{2+}\right)$ on humic acids and fulvic acids extracted from typical soils in China, Colloids and Surfaces A: Physicochemical and Engineering Aspects: 335, 194-201 (2009). 
